\title{
Introducing Team Coordination Framework to Support Globally Distributed Teams for Pakistani Software Industry
}

\author{
ZARTASHA GUL*, YASER HAFEEZ*, AMBER SARWAR HASHMI*, SADIAALI*, AND \\ NAILA IQBAL*
}

RECEIVED ON 03.12.2017 ACCEPTED ON 12.02.2018

\begin{abstract}
Collaborative effort is required in DSD (Distributed Software Development) in order to develop software in manageable components. Immense effort is taking place due to the cultural, geographical and temporal distances among project teams in Pakistani Software Industry to this end. The purpose of this study is to propose a solution during DSD that will help the distributed teams in coordinating their activities. Our solution enhances the management associated activities and assists in optimal usage of team coordination in dispersed settings. The method that we used is single case study type, which involved distributed software business to assess the usefulness and efficiency related to Pakistan's DSD industries, and has shown strong tendency of participants towards the effectiveness of proposed team coordination framework. Results indicate that the predictable solution will look up the group management, which is considered as a vigorous issue of Pakistani DSD industry. Furthermore, it will assist in resolving the problems of team coordination in distributed situation. One of the most significant current discussion about the proposed solution suggested that it helps in human communication methods team coordination in a distributed environment.
\end{abstract}

Key Words: Software Development of Distributed Software, Team Coordination, Centralized Cloud, Communication Mechanisms.

\section{INTRODUCTION}

$\mathrm{D}$ $\mathrm{SD}$ is considered as a collaborative activity in which team members work collectively to produce a product [1]. At the present time it is usual practice to have disseminated teams working together for producing a software product [2]. DSD locates the software team to disperse location throughout the software life cycle [3]. This practice has strengthened its roots to such an extent that it is becoming a standard for software development [4].
DSD research is highly interested in different merits such as highly skilled and cheap labor which is available across the border and round the clock in a working environment [5]. The quality of software development increases in DSD rapidly due to optimal usage of resources and cost saving [6]. In spite of benefits, the pitfalls of DSD cannot be ignored i.e. communication, team coordination and controls are the major issues [1-2].

Authors E-Mail: (zartasha.gul88@gmail, yasir@uaar.edu.pk, ambersarwar@hotmail.com, sadiaalief@gmail.com, nailaiqbal760@gmail.com) * University Institute of Information Technology, Pir Mehr Ali Shah Arid Agriculture University, Rawalpindi, Pakistan. 
In the new global development environment, team coordination is a central issue for outsource organization [3-4]. Hence, team coordination arises problems such as Response delay, Spontaneous informal communication, and Knowledge sharing due to decentralized team members as mentioned in existing studies [4-5]. In addition, we extracted the issues for Pakistani software DSD organizations through survey. Therefore, these problems result in inadequate communication, coordination, allocation of circumstance and unfortunate approach into development behavior [7]. For exchanging necessary project information, coordination is needed in a diverse environment by software teams. It can be defined as "to attain the project goals the deed of performing together amicably and dealing with interdependencies of tasks in which numerous actors are involved and several activities are performed" $[4,8]$.

Different teams are involved for the product development i.e. project management team, designing team, developer team etc. and all the teams work collectively. These teams coordinate for the organization and management of the production operations. Team coordination is an important determinant for team performance in software development especially in a disbursed environment. Team coordination is the interpersonal connections between members that are necessary for exchange of data, emerging and preserving communication designs and mutually agreed upon team up grades toward the constructing and conveying of an ordinary project [9].

Various activities in team coordination includes what has been done in software development such as effort coursework, assigning roles, work arrangement plus tasks, knowledge allocation and arranging processes [1,10-11]. In $\mathrm{DSD}$, there are various challenges like team coordination together with; problem in time zone differences, deficiency in collective ownership and trust, assignments of responsibilities and roles [12-13].

Hence in Pakistan for DSD the team coordination has played a vital role in project development and same major issues of team coordination are being faced by the software industry to attain the international standards of software development [14-15]. Therefore, team coordination raised issues in project management activities i.e. requirement analysis, architecture designing, development, unit testing etc. for synchronization of work [16-17].

It is approved that the coordination management is an additional action in DSD for the improvement of software development; as we conducted review in the Pakistani organization to identify the team coordination pitfalls. The selected organization based on Pakistani DSD and its offices situated in Denmark and Ireland. The major domain of project development of DSD organization is security and health relevant projects development. The review amongst the team members of Pakistani DSD organization conducted to identify the challenges of team coordination and result depicted that knowledge sharing response delay, Cultural differences, Language difference, Data management, spontaneous informal communication etc. are the reason of improper coordination amongst teams as highlighted in the existing literature [12-13]. Therefore, there is decrease in quality and increase in failure of projects due to improper synchronization in tasks.

In order to achieve effectual software development, there are some existing solutions proposed in literature to increasing proficiency in coordination/communication management, e.g. the ProxiScientia, tool supports project manager towards increased coordination transparency by informing team members regarding the job

Mehran University Research Journal of Engineering \& Technology, Volume 37, No. 4, October, 2018 [p-ISSN: 0254-7821, e-ISSN: 2413-7219] 
dependencies [11], Iris is used to solve coordination practices with agile method in distributed spreading [18-19] social media tools like Dropbox, G+, skype, Facebook tool etc. are used for project development and monitoring across boundaries [1,19-20]. Whereas, these is still need of efficient team coordination tools for better quality and higher customer satisfaction within limited resources as recommended by the Standish group report and version one report of UK instead of theoretical solutions.

All along by way of apparatus and structure, massive quantity of coordination apparatuses needs modifications to provide standardized coordination procedure, mutual fine-tuning and direct management [6]. Hence, Continuous coordination by process slanting approaches and informal knowledge distribution tactics are available to deal with coordination issues [21]. We proposed a framework that merged communiqué, coordination and project management behavior all along with the improvement process stream to moderate the disbursed development trouble. Therefore, this study improves team coordination in disbursed Pakistani software industry and shifts our conceptual framework into practice.

In Section 2, we describe related work dealing with team coordination challenges. Section 3 elaborates the materials and methods. Section 4 presents the results and discussion of conducted case study and section 5 concludes the respective research. Finally, section 6 discusses the future work.

\section{RELATED WORK}

Some existing research has been proposed to manage the team coordination difficulties in DSD. A structure incorporating coordination activities is introduced [22] across boundaries in a disbursed team. The proposed structure conspiracy of silence technological aspects also projects management solution aspects. Usage of collaborative apparatus facilitates the team Coordination. However, this solution not appropriate for the decisionmaking customization speed and knowledge management.

Redmiles et. al. [21] introduced the coordination supported tool i.e. ProxiScientia, which supports the project manager activities to increase coordination transparency by informing team members regarding their job dependencies. They suggest that some software engineering practices in a project named Iris gain more attention in globally spread team members due to allocating tasks by aligning and integrating their tasks. For coding, research community suggested that coordination challenges are dealt to collaborate. They put forward, that along with the collaborative coding, collaborative software engineering should also be in put in use [10].

Several scrum practices are suggested to be used in distributed environment to moderate problems of management, communication, and control in a detached environment. A case study was performed to estimate the impact of using scrum practices in distributed environment. Outcome showed that the scrum practices are also valued in distributed environment as they are in collocated settings [23].

By means of the powerful reputation of community medium there are some opinions to apply communal media in software development. A study presents examples showing how Facebook tool serves the software projects development and monitoring. Social media like Facebook

Mehran University Research Journal of Engineering \& Technology, Volume 37, No. 4, October, 2018 [p-ISSN: 0254-7821, e-ISSN: 2413-7219] 
is helpful in solving coordination, communication and other challenges of distributed environment for the reason to uphold online behavior of the whole day in the project [1]. Challenges about announcement, coordination, organization and information administration are described in [24]. Challenges as regards to announcement, coordination, organization and information administration are described in [25-26].

Literature and practitioners address the team coordination challenges by giving those assorted solutions intended for victorious team coordination behavior [17]. Email, scrum meetings and chat rooms are additional improvement practices for the victorious. Apart from the Github and Assembla a number of collaborative work spaces are also introduced to overcome team coordination issues [1]. Table 1 shows some problems of team coordination and their mitigation practices i.e. lack of face to face communication, Response delay, Cultural differences, Language difference etc. [1,27-30]. Although existing proposed solutions have helped in a noteworthy way and provided with significant benefits, they still have some flaws that need improvements [3].
All along by way of the apparatus and structure massive quantity of coordination mechanisms are prolonged to be introduced. Some described coordination mechanisms are standardization, mutual adjustment and direct supervision [6]. Continuous coordination is another explicated novel mechanism that merges some formal i.e. process slanting approaches, and informal knowledge distribution approaches to deal with coordination challenges [26].

The study proposed a framework merging communiqué, coordination and project management behavior all along with an improved process stream to moderate the dispersed development trouble.

\section{MATERIALS AND METHOD}

After the review of previous work dealing team coordination challenges; we identified problems and solutions by presenting and proposing the framework to improve Team coordination. At the end, a case study was conducted to evaluate the proposed framework. The complete flow chart of research process portrayed in Fig. 1.

TABLE 1. COORDINATION PROBLEMS IN DISTRIBUTED ENVIORNMENT AND THEIR POSSIBLE SOLUTIONS

\begin{tabular}{|c|c|c|}
\hline Coordination Problem with Distributed Teams & Possible Solution & Reference \\
\hline Lack of face to face communication & Video conferencing & {$[27,28]$} \\
\hline Response delay & Email notification & {$[31-32]$} \\
\hline Spontaneous informal communication & Instant messages & {$[33-34]$} \\
\hline Knowledge sharing & Discussion boards & {$[27,30]$} \\
\hline Cultural differences & Theme based interfaces & {$[1,8]$} \\
\hline Language difference & Language choice or language translator & {$[34]$} \\
\hline Unavailability of project management tools & Web based project management systems & {$[4,23,35]$} \\
\hline Data management & Database & {$[36]$} \\
\hline Managing documentations & Wikis and google docs etc. & {$[1,37]$} \\
\hline Replicating codes & Content versioning system & {$[4]$} \\
\hline Security of network & Encryption techniques & {$[38-39]$} \\
\hline Avoiding unauthorized access & Giving privileges & \\
\hline
\end{tabular}

Mehran University Research Journal of Engineering \& Technology, Volume 37, No. 4, October, 2018 [p-ISSN: 0254-7821, e-ISSN: 2413-7219] 
Team coordination has a vital impact in the success of any project. However, with the enormous amount of benefit, team coordination has some menaces in the Software industry of Pakistan [14-15]. The literature review has highlighted these challenges. These identified barriers are investigated and considered to be removed from the Pakistani Software Industry.

A framework has been proposed with a proper sequence of activities, which involves the improved practices of coordination throughout the development cycle. Fig. 2 illustrate our team coordination proposed framework for mitigating challenges for the improvement in Pakistan Software Industry at different phases of software development using cloud. The cloud environment provides centralized online repository for all team members for synchronization of their works/activities at single platform instead of multiple sites for interconnections amongst teams.
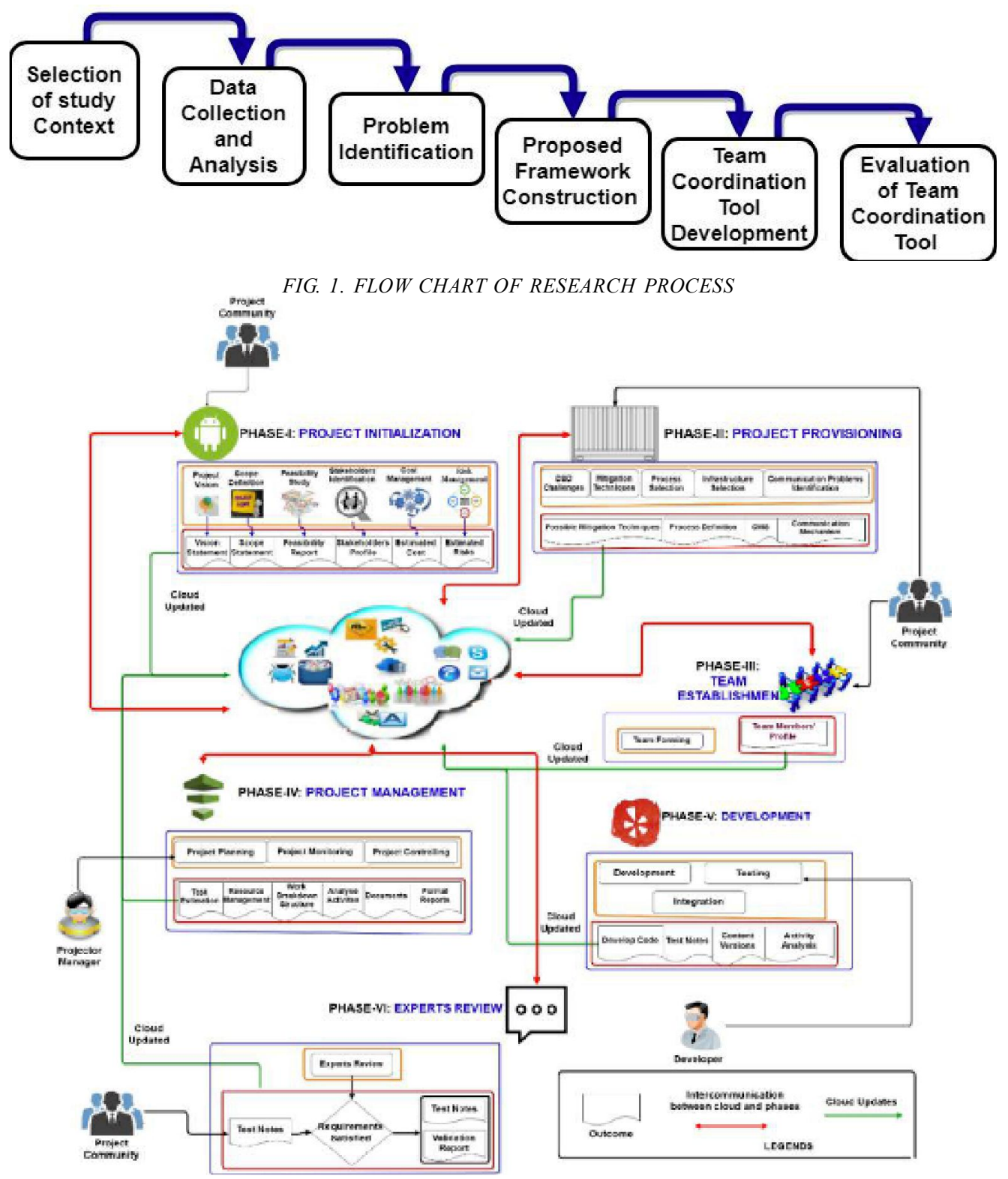

FIG. 2. PROPOSED FRAMEWORK SUPPORT TEAM COORDINATION

Mehran University Research Journal of Engineering \& Technology, Volume 37, No. 4, October, 2018 [p-ISSN: 0254-7821, e-ISSN: 2413-7219] 
Phase-1: Project Initialization: In this stage the risk management and cost management are completed through tools accessible. Feasibility report is generated by the feasibility study; generated scope will be defined to develop scope statement. Then we will prepare the project vision document, a register of everyone stakeholder is moreover recognized and update in the cloud repository.

Phase-II: Project Provisioning: The structure classifies DSD challenges, their appropriate solutions, plus suitable structure collection. Result of phase 2 is clearly distinct procedure for the close to plan, prototype managing system and statement mechanism.

Phase-III: Team Establishment: Behind the recognition of a suitable structure the team configuration is the subsequently connected technical surroundings are selected through online interviews. Team members profile is the work of art of the existing phase. Cloud will generate the summary to assist in transmission suitable roles and duties among members.

Phase-IV: Project Management: This phase emphasizes the planning analysis activities, calculating cost and monitoring activities assigned among members of teams with respect to their capabilities. The result formally enlisted in Work Breakdown Structure, resource assessment, visualized activities, documents and executive reports. The project controlling maintenance of the team members is on the pathway.

The central purpose of the proposed solution is to perk up the team coordination amongst group members. Table 1 shows the team coordination problems and their available solutions.

Phase-V: Development: The development team plays an essential role in the development of tasks and developed software modules which are the deliverables. This phase produce results as per test notes and tested code. The functional system or any functional module is totally incorporated in cloud.

Phase-VI: Later the reviews are conducted for deficiency elimination for formal review, and the validation report.

We use cloud environment for the implementation of our conceptual framework since cloud provides the presentation prototype (for proof of concepts and explaining design functionality) and exploratory prototype (to determine complications, elicit needs, clarify goals, compare design options) [24,40]. The purpose of the cloud paradigm is to eliminate installation that works towards reducing cost and presents other rewards such as trouble-free utilization, straight forward scalability, improved performance and cost minimization $[24,40]$. In order to avail these competent services of cloud, the proposed framework proposes that the project community will maintain their own cloud. The cloud will be rooted with the coordination mechanisms such as content versioning system, language translator, discussion forums etc.

\subsection{Motivation for Using Cloud}

Coordination is cheerlessly pretentious in geographic distances and are a series of attempts during DSD. This provides services, runtime binding and dynamic adaptation, diminishing of installation overhead at each location, centralized data existence, maintenance of services inventory, storage and retrieval of configurations [33]. Therefore, while keeping the current barriers of Pakistan Software Industry, usage of cloud approach will ensure the immense benefits of team coordination.

Mehran University Research Journal of Engineering \& Technology, Volume 37, No. 4, October, 2018 [p-ISSN: 0254-7821, e-ISSN: 2413-7219] 


\subsection{Tool Architecture}

The ultimate goal of our research is to shift our conceptual framework into practice in order to provide proof of concepts. For our team coordination proposed framework to improve the team coordination for performance analysis used the $\mathrm{N}$ tiered model view architecture which used to change view-based architecture to action based architecture for formulating an abstract architecture [41] before heading towards tool's formation. The Fig. 3 shows architecture of the proposed system. Architecture is comprised of the 3 layers; the presentation layer, Business logic layer and Data access layer. Proposed framework involves cloud support, thus cloud infrastructure and cloud services are in provision with the architecture. Bottom layer of the architecture is data access layer. It contains data access components and data utilities. This layer is the bridge to the relational record and objectoriented database management system. Centre layer is the business logic layer.
Controller classes reside in business layer, and these classes signify the use of case managers that determine the application performance. Business layer characterizes the client-to-mid-tier edge. This business services layer pivots on the process objects layer; which embraces the parting of mid-tier from client. Top most layer of the proposed application is presentation layer. This layer comprised of everyone the graphical interfaces that are visible to users. Process objects layer governs the application layer and this process object layer separate mid-tier from client. Top part of the architecture in Fig. 3 represented that the user can access the request using any web browser. Cloud communications and cloud services provide the cloud support to the application. This support would be regarding to the deployment model of the cloud.

\subsection{Tool Description}

A tool is the architecture of team coordination proposed framework. The architecture serves as the high-level

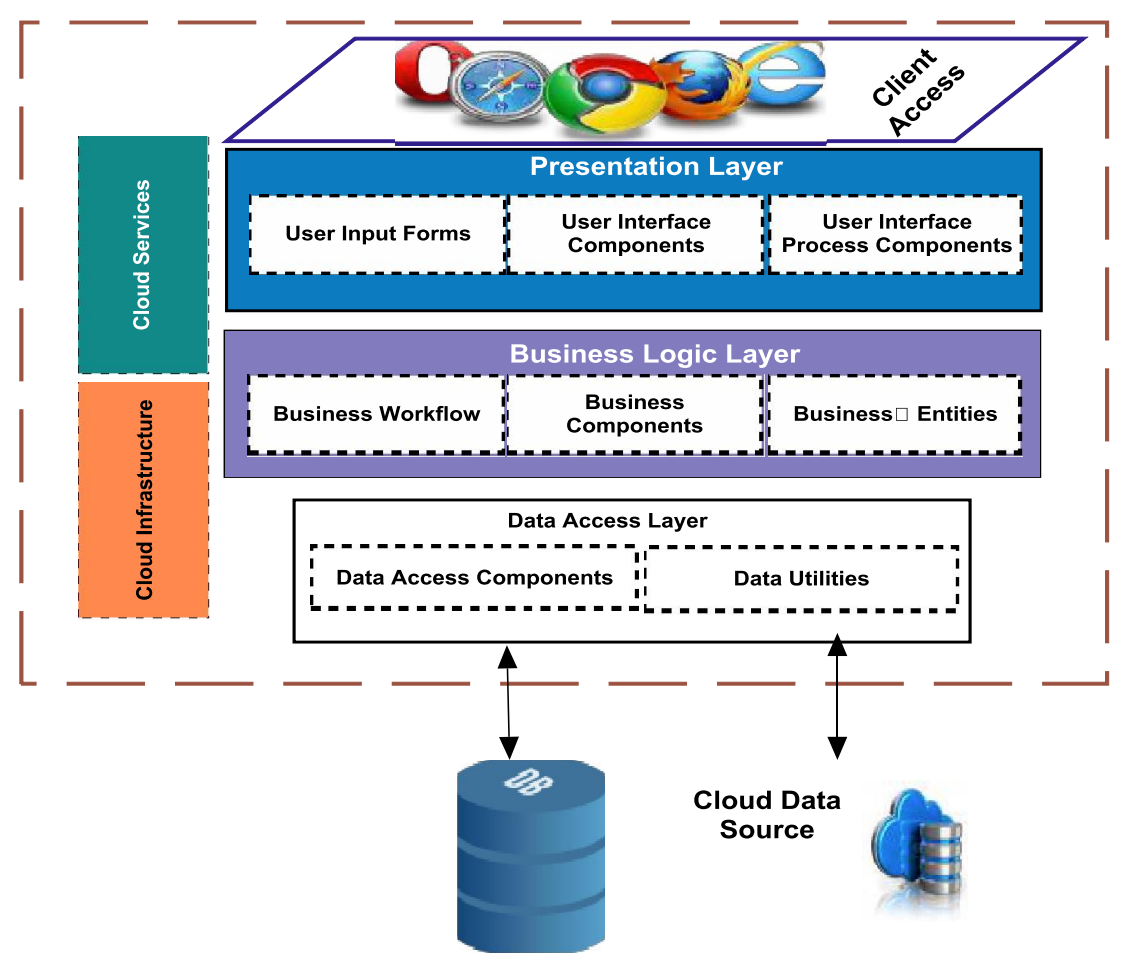

FIG. 3. TOOL ARCHITECTURE

Mehran University Research Journal of Engineering \& Technology, Volume 37, No. 4, October, 2018 [p-ISSN: 0254-7821, e-ISSN: 2413-7219] 
design to shift conceptual approach to working prototype for incorporating and characterizing components and connectors. Thus, we evaluate our team coordination tool with existing tool i.e. MantisBT system used in distributed environments of Pakistan software industry.

We also compared our tool with existing tools on the base parameters selected from the existing literature. The comparative analysis used for tool effectiveness and results are portrayed in section 4. The tool is fully functional for developing the project in software company for evaluation and comparison with real scenario and existing tools. Meanwhile, section describes features and uses of developed tool on the base of team coordination proposed framework. Focal point of the research is team coordination, thus modules containing team coordination practices are described here. We include only mandatory design screen shots of tools to elaborate the functionality of team coordination instead of complete design.

System Dashboard: Fig. 4 represented system dashboard of the user. After logging in, every team member would have his/her system dashboard performance tasks assigned to him/her and current activities of the project to which he/she is team member. This will have improved the team coordination as team affiliate dose not have required coordinating for the assignment of tasks. This will also improve team activity awareness.

Discussion Forums: Discussion forum is additional in coordination module to hold up team coordination in proposed system. All team members concerned in the existing project can share their views, ask questions with reference to the existing activities and add comments on project. Fig. 5. shows discussion board of the planned system.

The proposed framework support team coordination tool other functionality attached in the Appendix-I.

\section{RESULTS AND DISCUSSION}

Evaluation of proposed solution is an imperative activity which cannot be overlooked. After providing the solution for the coordination problem in DSD, case study is adopted to evaluate the projected solution.

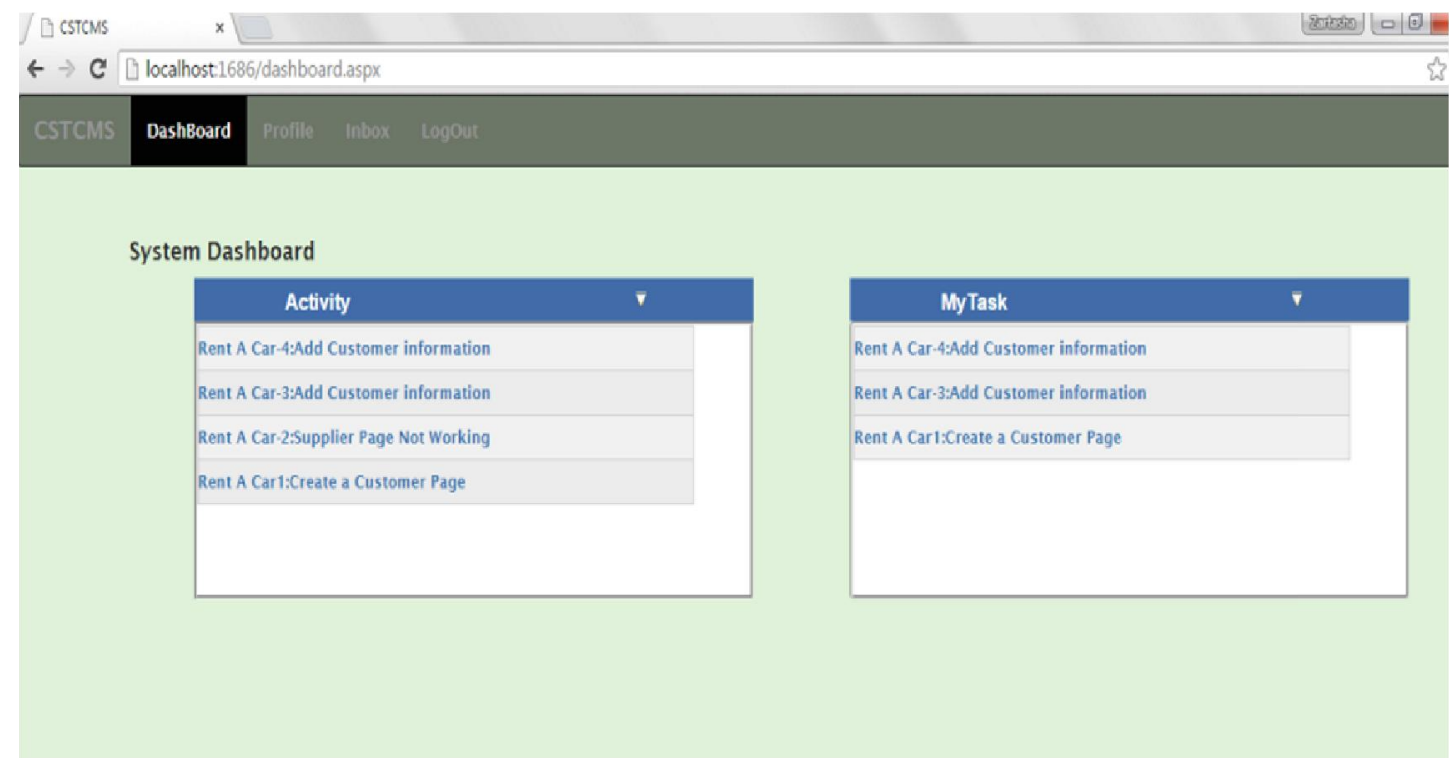

FIG. 4. DASHBOARD OF THE USER

Mehran University Research Journal of Engineering \& Technology, Volume 37, No. 4, October, 2018 [p-ISSN: 0254-7821, e-ISSN: 2413-7219] 


\subsection{Case Study}

An organization was selected to investigate the proposed phenomenon. Vendor based distributed software organization did not allow us to mention their name due to their privacy. Organization has offered many successful distributed projects. Testing of the selected MantisBT system is also performed at distributed locations. The company supports the disseminated development. The Team Coordination (Proposed Framework) was used to test the selected system to evaluate the effectiveness of team coordination resolution in distributed environment. Team occupied in development and testing of the selected case helped in evaluating the proposed solution. Questionnaires and interviews were the techniques used to gather information about the evaluation.

We selected the Rent a car company which developed same system with our Team coordination tool and MantisBT system approaches. Reviews are taken from team members, who used the proposed research solution in testing the selected case study. Reviews are taken to compare the results of both approaches. After the completion of the testing of case study, team members are given some parameters for the sake of evaluation. Participants are asked about the parameters such as: user satisfaction, ease of use, improved efficiency, understand ability, improved team coordination and cost advantage.

The data of reviews from both the teams who developed project using our proposed framework presented in Tables 2-3 presented the results of team who developed project without our proposed framework. Figs. 6-7 show the results of case study. The $\mathrm{x}$-axis represents the assessments of factors for evaluation; whereas, y-axis represents the rating scale of participants. The results depicted that in the case our team coordination tool, most of the participants strongly agreed and also agreed with performance and team coordination issues resolution. Whereas, in case of MantisBT Systemmost of the participants were not fully satisfied.

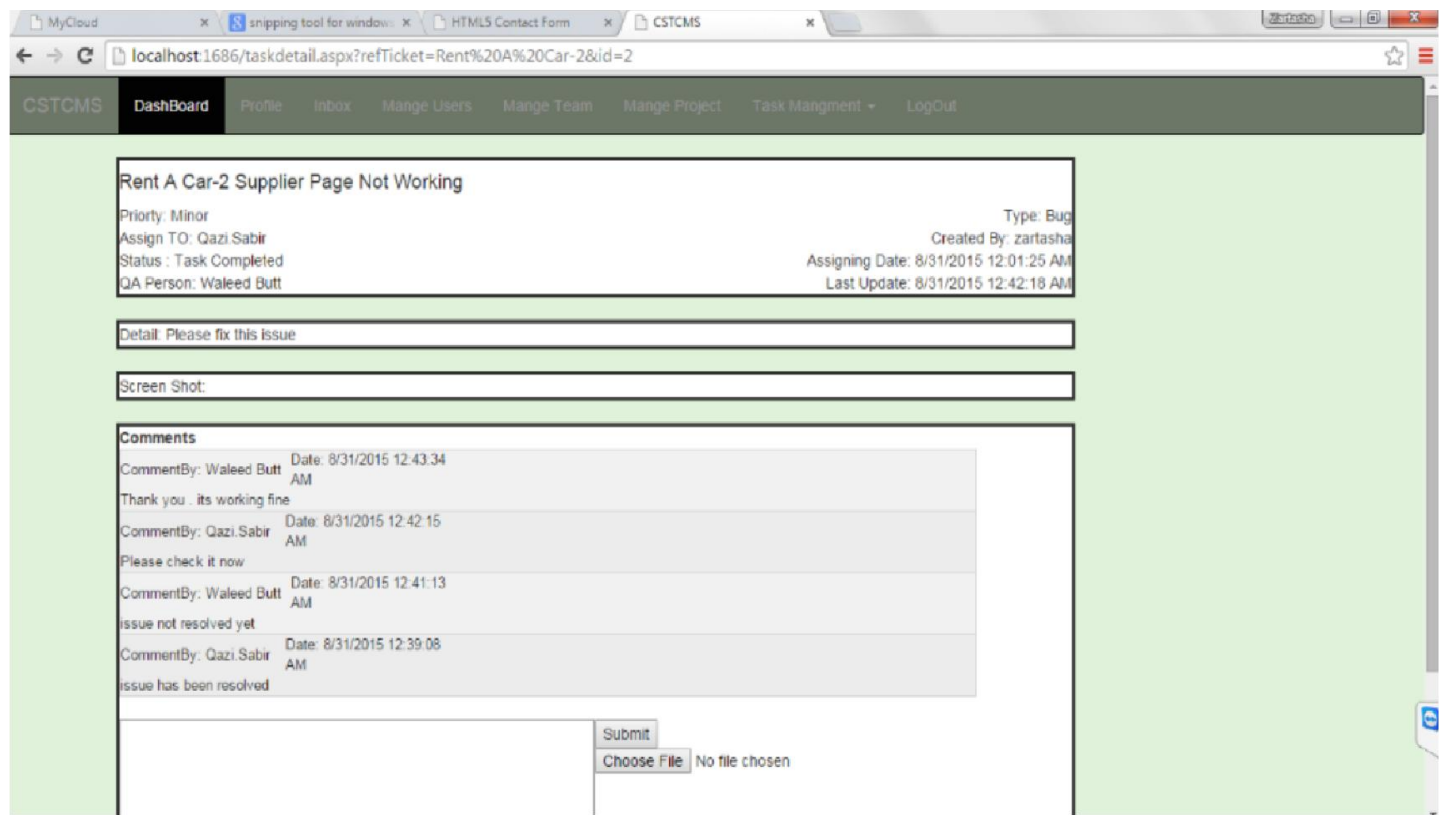

FIG. 5. DISCUSSION FORUM

Mehran University Research Journal of Engineering \& Technology, Volume 37, No. 4, October, 2018 [p-ISSN: 0254-7821, e-ISSN: 2413-7219] 
Results of survey showed that contestants have wellbuilt tendency towards strongly agreed. There are very few respondents having attention towards disagreed and approximately no responses (minute) are recorded towards strong conflict. From the result, situation can be analyzed that the respondents are confident towards the proposed solution. Results showed that solution solves problems and supervise the team coordination performance in circulated environment with efficient improvement, higher satisfaction, understandability and cost benefit in scattered zones.

The selected parameters are a vital for tool evaluation and used in the existing studies i.e. [25,35-36,39] for the assessment of the proposed working system. The
MantisBT is used to develop the selected system and proposed tool is used to test the system, so reviews are gathered to compare the effectiveness of team coordination of both systems. Fig. 6 shows results for proposed system and Fig. 7 shows results of compared system. It can be clearly seen in the difference graph that the proposed solution has improved the team coordination than the compared system.

\subsection{Comparison with Existing Tools}

Table 4 shows the comparison of the proposed solution with the existing tools. Comparison is performed only for the coordination module of the existing tools as the solution is proposed to deal with

TABLE 2. TEAM COORDINATION (PROPOSED FRAMEWORK)

\begin{tabular}{|c|c|c|c|c|}
\hline Parameters & Strongly Agreed & Agreed & Partially Agreed & Not Agreed \\
\hline User Satisfaction & 3 & 1 & 1 & 0 \\
\hline Ease of Use & 3 & 1 & 0 & 1 \\
\hline Improved Efficiency & 2 & 2 & 0 & 1 \\
\hline Understand Ability & 2 & 2 & 1 & 0 \\
\hline Improved Team Coordination & 2 & 2 & 1 & 0 \\
\hline Cost Advantage & 2 & 2 & 1 \\
\hline
\end{tabular}

TABLE 3. MANTISBT SYSTEM

\begin{tabular}{|c|c|c|c|c|}
\hline Parameters & Strongly Agreed & Agreed & Partially Agreed & Not Agreed \\
\hline User Satisfaction & 1 & 1 & 2 & 1 \\
\hline Ease of Use & 0 & 1 & 2 & 2 \\
\hline Improved Efficiency & 1 & 2 & 1 & 2 \\
\hline Understand Ability & 0 & 2 & 1 & 1 \\
\hline Improved Team Coordination & 1 & 2 & 1 & 2 \\
\hline Cost Advantage & 0 & 2 & 2 & 2 \\
\hline
\end{tabular}

Mehran University Research Journal of Engineering \& Technology, Volume 37, No. 4, October, 2018 [p-ISSN: 0254-7821, e-ISSN: 2413-7219] 
the team coordination activities. The comparison Table 4 shows that the existing tools are generic, their focus is towards project management activities. Very few of the existing tool incorporate team coordination problems solutions especially in distributed environment and these solutions provide different interfaces or websites to deal with team activities. Our team coordination proposed framework will help the software industry to mitigate team coordination problems while developing software in distributed environment of Pakistani industry using cloud computing. The Table 4 presented that our proposed framework support team coordination provides most of the required functionality mentioned as compared to existing tools.
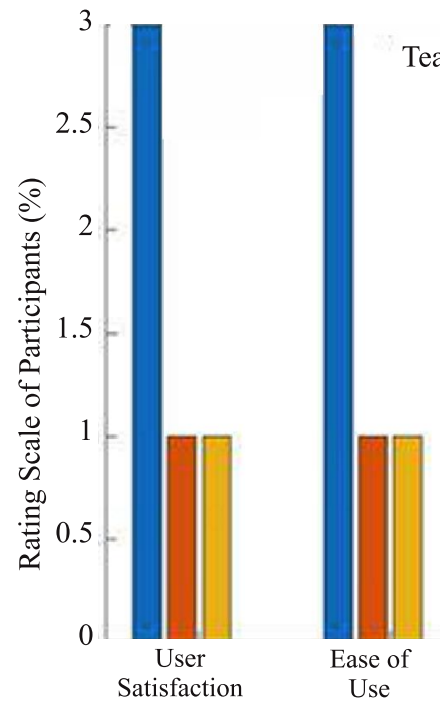

Team Coordination (Proposed Framework)
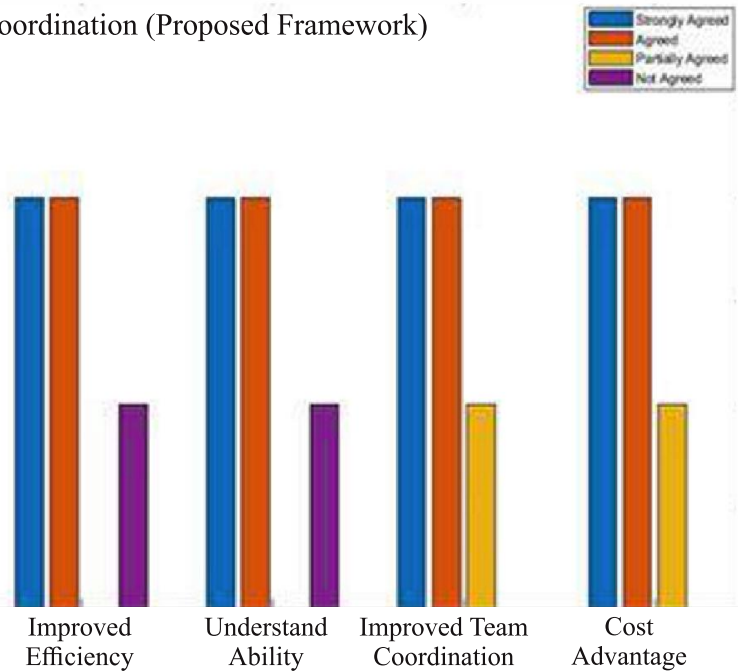

Assessment Factors for Evaluation

FIG. 6. RESULTS OF TEAM COORDINATION (PROPOSED FRAMEWORK)

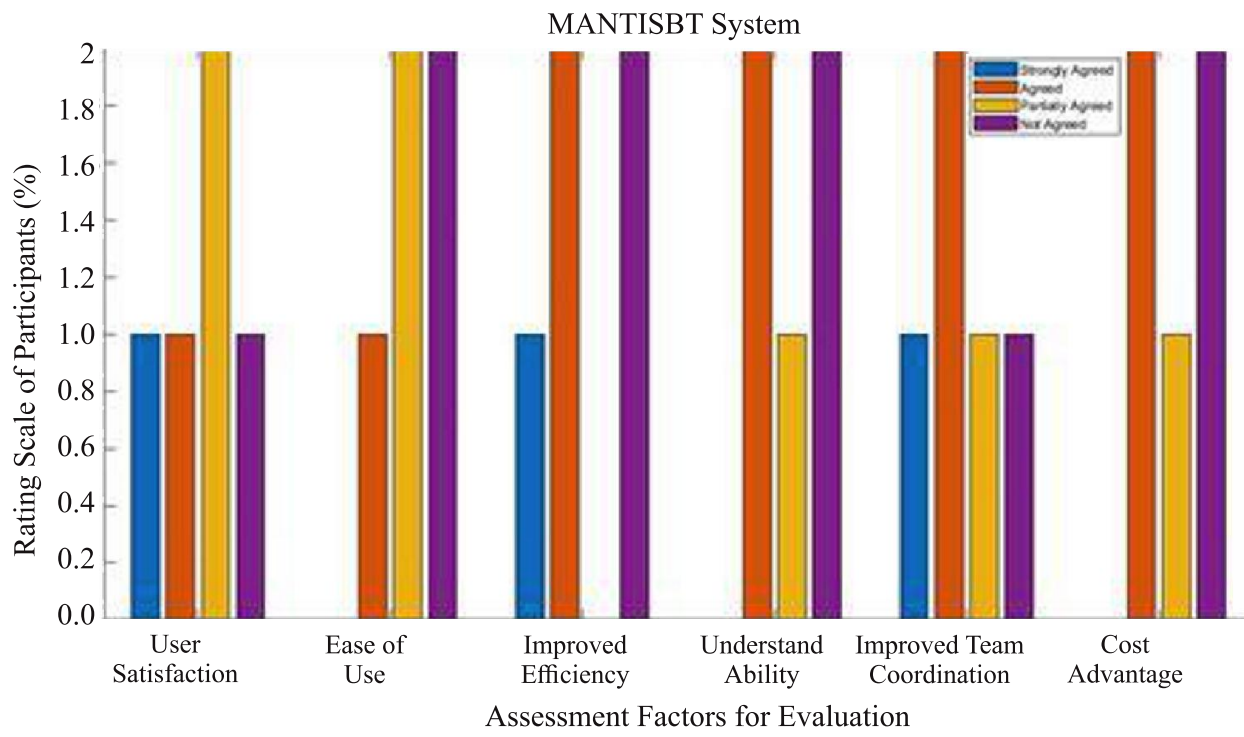

FIG. 7. RESULTS OF MANTISBT SYSTEM

Mehran University Research Journal of Engineering \& Technology, Volume 37, No. 4, October, 2018 [p-ISSN: 0254-7821, e-ISSN: 2413-7219] 
TABLE 4. COMPARISON WITH EXISTING TOOLS

\begin{tabular}{|c|c|c|c|c|c|c|c|c|c|}
\hline \multirow{2}{*}{ Existing Tools } & \multicolumn{9}{|c|}{ Team Coordination Framework } \\
\hline & $\begin{array}{c}\text { Discussion } \\
\text { Boards }\end{array}$ & CVS & Translators & Standardization & Cloud & Email & IM & $\begin{array}{c}\text { Video } \\
\text { Conferencing }\end{array}$ & Telephone \\
\hline $\begin{array}{c}\text { Team Coordination } \\
\text { (Proposed } \\
\text { Framework) }\end{array}$ & $\checkmark$ & $\checkmark$ & $\checkmark$ & $\checkmark$ & $\checkmark$ & $\checkmark$ & $\sqrt{ }$ & $\checkmark$ & $\checkmark$ \\
\hline Jira & $\checkmark$ & $\checkmark$ & $x$ & $x$ & $x$ & $\mathrm{P}$ & $x$ & $x$ & $x$ \\
\hline Costar & $x$ & $x$ & $x$ & $x$ & $x$ & $\mathrm{P}$ & $x$ & $x$ & $x$ \\
\hline QSM Slim & $\mathrm{P}$ & $x$ & $x$ & $x$ & $x$ & $x$ & $x$ & $x$ & $x$ \\
\hline Twiki & $x$ & $\checkmark$ & $x$ & $x$ & $x$ & $\checkmark$ & $x$ & $x$ & $x$ \\
\hline Assembla & $\checkmark$ & $x$ & $x$ & $x$ & $x$ & $\mathrm{P}$ & $\sqrt{ }$ & $\checkmark$ & $x$ \\
\hline Active Collab & $\checkmark$ & $\checkmark$ & $x$ & $x$ & $x$ & $\checkmark$ & $x$ & $x$ & $x$ \\
\hline MS Sharepoint & $\checkmark$ & $\checkmark$ & $x$ & $x$ & $x$ & $\checkmark$ & $x$ & $x$ & $x$ \\
\hline e-Groupware & $x$ & $x$ & $x$ & $x$ & $x$ & $\checkmark$ & $x$ & $x$ & $x$ \\
\hline Open Exchange & $x$ & $\mathrm{P}$ & $x$ & $x$ & $x$ & $\checkmark$ & $x$ & $x$ & $x$ \\
\hline Mantis & $x$ & $\mathrm{P}$ & $x$ & $x$ & $x$ & $\checkmark$ & $x$ & $x$ & $x$ \\
\hline Completely Com & $=" \sqrt{ } "$ & & & Partially Com & $=$ "P" & & & Not Compil & $=" \boldsymbol{X} "$ \\
\hline
\end{tabular}

\section{CONCLUSION}

Our contribution in research is discovery of the team coordination challenges due to sequential, environmental, cultural alterations and their recommended mitigation practices. This study improves team coordination in Pakistani disseminated progress of software. It is claimed that communication is a significant issue and must be improved for better collaboration amongst dispersed teams. Our team coordination proposed framework provides both theoretical and practical solution for the practitioners to improve quality, satisfaction and more foreign returns within limited resources. We used both formal and informal communiqué mechanisms for teams to collaborate effectively. This study reveals the stateof-practice DSD activities and cloud adoption in the context of Pakistani Software Industry. Our proposed framework also improving communication structure for better team coordination during working in Pakistani DSD environment. The results depicted that the conceivable solution enhanced team synchronization in DSD.

\section{FUTURE WORK}

In our future work, we will improve control and management of the vitality of requirements in a distributed environment, with mapping the change alongside its implementation. Similar investigations can be shown with a larger set of cases across the globe, which helps to increase the generalizability of our findings on cloud. We also plan to perform an empirical study to confirm our findings in a large scale DSD industry.

\section{ACKNOWLEDGEMENT}

This work has been taken partially from Thesis (First Author). Authors are grateful for the support of parents and faculty of Pir Mehr Ali Shah Arid Agriculture University, Rawalpindi, Pakistan. Authors would also like to thank Internal and External Referees, for their wisdom, suggestions and endless support, throughout our paper. 
APPENDIX-I: OTHER FEATURES OF PROPOSED FRAMEWORK SUPPORT TEAM COORDINATION

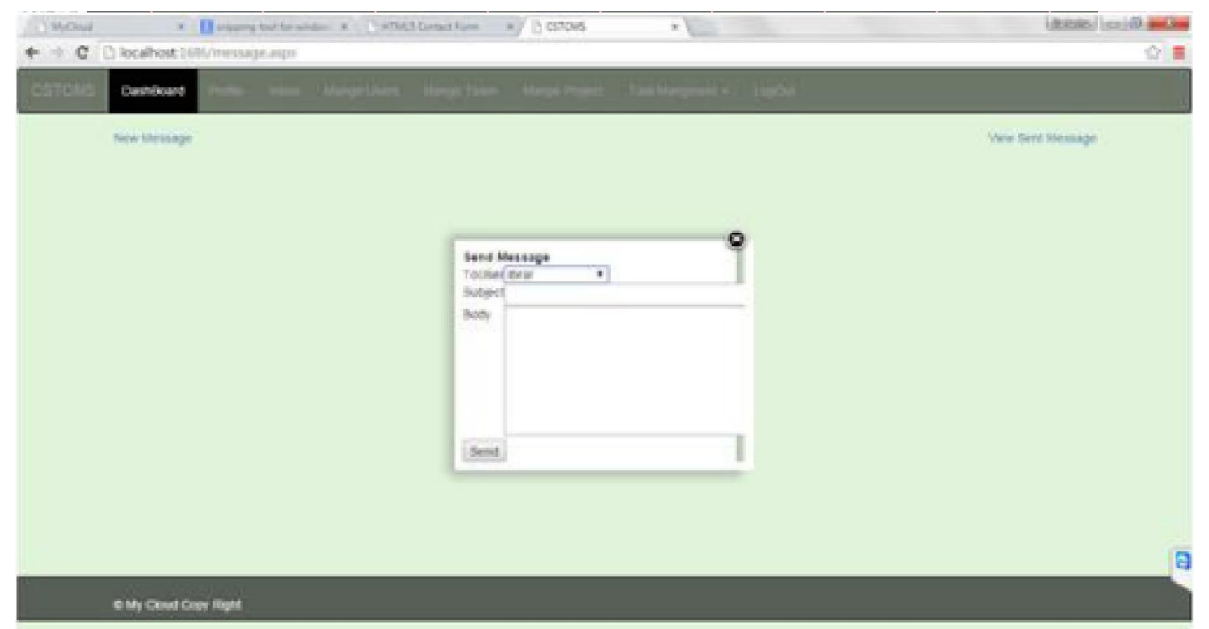

Instant Messages

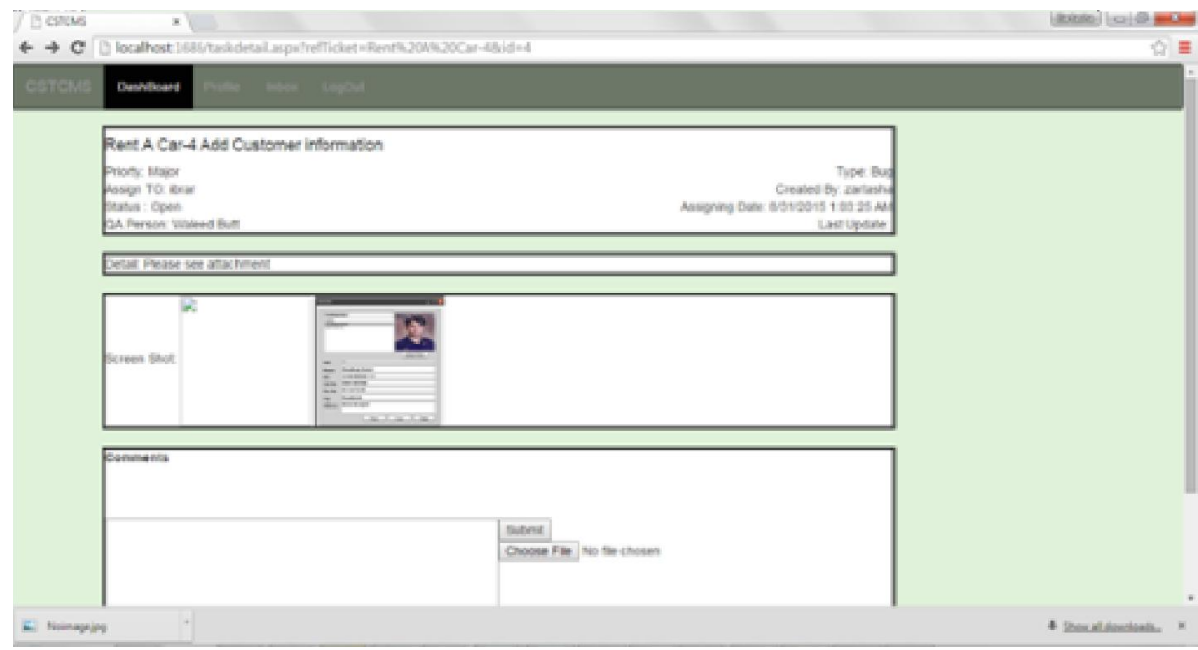

Translators

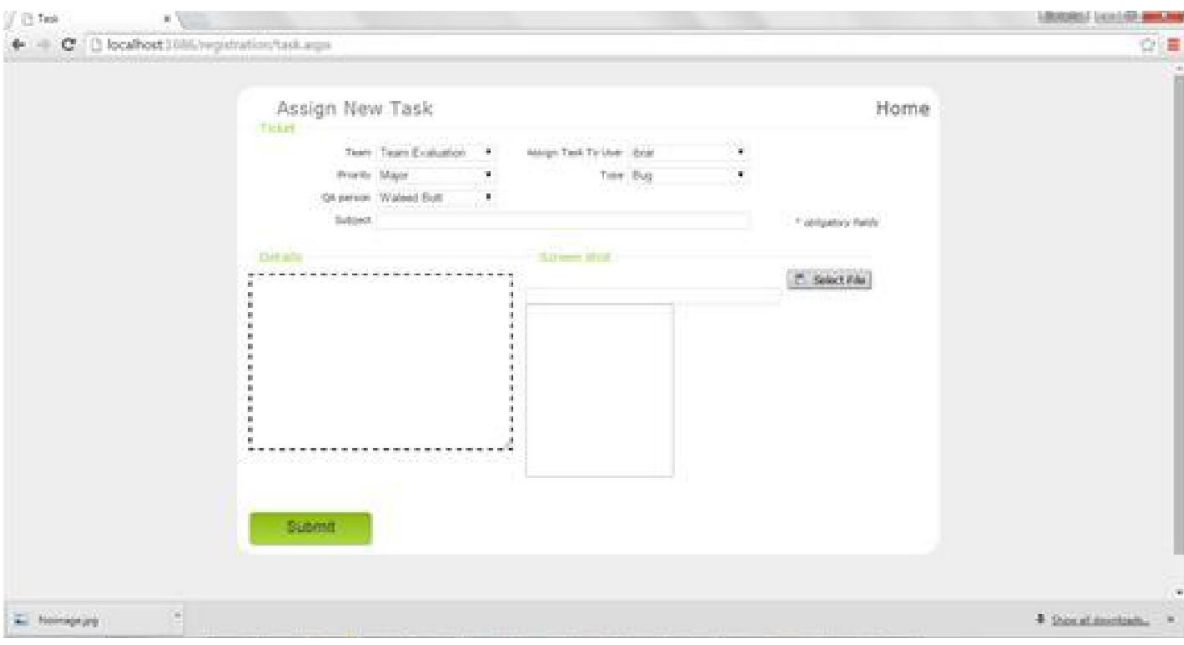

Task Assignment

Mehran University Research Journal of Engineering \& Technology, Volume 37, No. 4, October, 2018 [p-ISSN: 0254-7821, e-ISSN: 2413-7219] 


\section{REFERENCES}

[1] Juarez-Ramirez, R., Pimienta-Romo, R., and OceguedaMiramontes, V., "Supporting the Software Development Process Using Social Media: Experiences with Student Projects", Proceedings of IEEE 37th Annual Conference Workshop on Computer Software and Applications Conference Workshops, Computer Society, pp. 656-661, Washington, DC, USA, 2013.

[2] Herbsleb, J.D., "Global Software Engineering: The Future of Socio-Technical Coordination", Proceedings of IEEE Conference on Future of Software Engineering, Computer Society, pp. 188-198, Washington, DC, USA, 2007.

[3] Jiménez, M., Piattini, M., and Vizcaíno, A., "Challenges and Improvements in Distributed Software Development: A Systematic Review", Advances in Software Engineering, New York, USA, 2009

Deshpande, S., Beecham, S., and Richardson, I., "Using the PMBOK Guide to Frame GSD Coordination Strategies", Proceedings of IEEE 8th International Conference on Global Software Engineering, pp. 188-196, Bari, Italy, 2013.

Bannerman, P.L., Hossain, E., and Jeffery, R., "Scrum Practice Mitigation of Global Software Development Coordination Challenges: A Distinctive Advantage?", Proceedings of 45 th Hawaii International Conference on System Science, pp. 5309-5318, Maui, HI, USA, 2012.

[6] Šmite, D., Moe, N.B., and Torkar, R., "Pitfalls in Remote Team Coordination: Lessons Learned from a Case Study", Proceedings of International Conference on Product Focused Software Process Improvement, pp, 345-359, Springer Berlin Heidelberg, 2008.

[7] Omoronyia, I., Ferguson, J., Roper, M., and Wood, M., "A Review of Awareness in Distributed Collaborative Software Engineering: Software: Practice and Experience", Limerick, pp, 1107-1133, Ireland, 2010.

[8] Anh, N.D., Cruzes, D.S., and Conradi, R, "Dispersion, Coordination and Performance in Global Software Teams: A Systematic Review", Proceedings of ACMIEEE International Symposium on Empirical Software Engineering and Measurement, pp. 129-138, Lund, Sweden, 2012.
[9] Smite, D., and Dingsøyr, T., "Fostering Cross-Site Coordination through Awareness: An Investigation of State-of-the-Practice through a Focus Group Study”, Proceedings of 38th EUROMICRO Conference on Software Engineering and Advanced Applications, pp. 337-344, Cesme, Izmir, Turkey, 2012.

[10] Monteiro, A., Mêda, P., and Martins, J.P., "Framework for the Coordinated Application of Two Different Integrated Project Delivery Platforms", Automation in Construction, pp. 38, 87-99, 2014.

[11] Borici, A., Blincoe, K., Schröter, A., Valetto, G., and Damian, D., "Proxiscientia: Toward Real-Time Visualization of Task and Developer Dependencies in Collaborating Software Development Teams", Proceedings of 5th International Workshop on Cooperative and Human Aspects of Software Engineering, pp. 5-11, Zurich, Switzerland, 2012.

[12] Avritzer, A., Paulish, D., Cai, Y., and Sethi, K., "Coordination Implications of Software Architecture in a Global Software Development Project", Journal of Systems and Software, pp. 1881-1895, 2010.

[13] Begel, A., DeLine, R., and Zimmermann, T., "Social Media for Software Engineering", FoSER, pp. 33-38, St. Fe, New Mexico, USA 2010.

[14] Sultana, S., Motla, Y.H., Asghar, S., Jamal, M. and Azad, R., "A Hybrid Model by Integrating Agile Practices for Pakistani Software Industry”, IEEE International Conference on Electronics, Communications and Computers, pp. 256-262, February, 2014.

[15] Butt, F.S., Liaqat, M., Khan, M.R., Nisar, W., and Munir, E.U., "Common Factors in the Successful Software Projects in Pakistan's Software Industry”, World Applied Sciences Journal, Volume 23, No. 9, pp. 1176-1185, 2013.

[16] Cataldo, M., and Herbsleb, J.D., "Coordination Breakdowns and their Impact on Development Productivity and Software Failures", IEEE Transactions on Software Engineering, pp.343-360, 2013. 
[17] Akbar, R., and Hassan, M.F., "Limitations and Measures in Outsourcing Projects to Geographically Distributed Offshore Teams", International Symposium on Information Technology, pp. 1581-1585, Kuala Lumpur, Malaysia, 2010.

[18] Qahtani, A., Wills, G., and Gravell, A., “A Framework of Challenges and Key Factors for Applying Agile Methods for the Development and Customization of Software Products in Distributed Projects", International Journal of Digital Society, pp. 766-773, 2013.

[19] Begel, A., Nagappan, N., Poile, C., and Layman, L., "Coordination in Large-Scale Software Teams", Proceedings of IEE Workshop on Cooperative and Human Aspects on Software Engineering, Computer Society, pp. 1-7, Washington, DC, USA, 2009.

Furniss, D., Back, J., Blandford, A., Hildebrandt, M., and Broberg, H., "A Resilience Markers Framework for Small Teams", Reliability Engineering \& System Safety, pp. 2-10, 2011.

[2 1] Redmiles, D., Van Der Hoek, A., Al-Ani, B., Hildenbrand, T., Quirk, S., Sarma, A., and Trainer, E., "Continuous Coordination - A New Paradigm to Support Globally Distributed Software Development Projects", Wirtschafts Informatik, Volume 49, No. 1, 2007.

[22] Qahtani, A.M., Wills, G.B., and Gravell, A.M., "Toward a Framework for the Development and Specialization of Product Software Across Organizational Boundaries”, International Conference on Information Society (i-Society), pp. 391-395, London, UK, 2012.

[23] Carmel, E., and Agarwal, R., "Tactical Approaches for Alleviating Distance in Global Software Development", IEEE Software,Computer Society, pp. 22-29, 2001.

[24] Cocco, L., Mannaro, K., andConcas, G., "A Model for Global Software Development with Cloud Platforms", 38th EUROMICRO Conference on Software Engineering and Advanced Applications, pp. 446-452, Cesme, Izmir, Turkey, 2012.

[25] Baird, A., and Riggins, F.J., "Planning and Sprinting: Use of a Hybrid Project Management Methodology within a CIS Capstone Course”, Journal of Information Systems Education, Volume 23, No. 3, 2012.
[26] Tariq, A., and Khan, A.A., "Framework Supporting Team and Project Activities in Global Software Development", International Conference on Emerging Technologies, pp. 1-6, Islamabad, Pakistan, 2012.

Richardson, I., Casey, V., Mccaffery, F., Burton, J., and Beecham, S., “A Process Framework for Global Software Engineering Teams", Information and Software Technology, Volume 54, No.11, pp.1175-1191, Elsevier, 2012 .

[28] Anh, N.D., Cruzes, D.S., and Conradi, R, "Dispersion, Coordination and Performance in Global Software Teams: A Systematic Review”, ACM-IEEE International Symposium on Empirical Software Engineering and Measurement, pp. 129-138, Lund, Sweden, 2012.

[29] Nguyen-Duc, A., Cruzes, D.S., and Conradi, R., "The Impact of Global Dispersion on Coordination, Team Performance and Software Quality-A Systematic Literature Review", Information and Software Technology, pp. 277-294, Elsevier, 2015.

[30] Shiroma, P.M., and Campos, M.F., "CoMutaR: A Framework for Multi-Robot Coordination and Task Allocation", International Conference on Intelligent Robots and Systems, pp. 4817-4824, Louis, MO, USA, 2009 .

[31] Nordio, M., Estler, H.C., Meyer, B., Aguirre, N., Prikladnicki, R., Di Nitto, E., and Savidis, A., "An Experiment on Teaching Coordination in a Globally Distributed Software Engineering Class", IEEE 27th Conference on Software Engineering Education and Training, pp. 109-118, Klagenfurt, Austria, 2014.

[32] Nguyen-Duc, A., and Cruzes, D.S., "Coordination of Software Development Teams Across Organizational Boundary - An Exploratory Study", IEEE 8th International Conference on Global Software Engineering, pp. 216-225, Bari, Italy, 2013.

[33] Hashmi, S.I., Clerc, V., Razavian, M., Manteli, C., Tamburri, D.A., Lago, P., and Richardson, I., "Using the Cloud to Facilitate Global Software Development Challenges", $6^{\text {th }}$ IEEE International Conference on Global Software Engineering Workshop, pp.70-77, Helsinki, Finland, 2011. 
[34] Portillo-Rodriguez, J., Vizcaino, A., Ebert, C., and Piattini, M., "Tools to Support Global Software Development Processes: A Survey", 5th IEEE International Conference on Global Software Engineering, pp.13-22, Princeton, NJ, USA, 2010.

[35] Bannerman, P.L., Hossain, E., and Jeffery, R., "Scrum Practice Mitigation of Global Software Development Coordination Challenges: A Distinctive Advantage?", 45th IEEE International Conference on System Science, pp. 5309-5318, Maui, HI, USA, 2012.

[36] Dullemond, K., van Gameren, B., and van Solingen, R., "Collaboration Should Become a First-Class Citizen in Support Environments for Software Engineers", 8th International Conference on Collaborative Computing: Networking, Applications and Worksharing, pp. 398-405, Pittsburgh, PA, USA, 2012.

[37] Grambow, G., Oberhauser, R., and Reichert, M., "Towards Automatic Process-Aware Coordination in Collaborative Software Engineering", 6th International Conference on Software and Data Technologies, pp. 5-14, Seville Spain, 2011.
[38] Amin, A., Basri, S., Hassan, M.F., and Rehman, M. "Occupational Stress, Knowledge Sharing and GSD Communication Barriers as Predictors of Software Engineer's Creativity", IEEE International Conference on Industrial Engineering and Engineering Management, pp. 394-398, Singapore, 2011.

[39] Yildiz, B.M., Tekinerdogan, B., and Cetin, S., "A Tool Framework for Deriving the Application Architecture for Global Software Development Projects", IEEE $7^{\text {th }}$ International Conference on Global Software Engineering, pp. 94-103, Porto Alegre, Brazil, 2012.

[40] Yau, S., and An, H., "Software Engineering Meets Services and Cloud Computing", IEEE Computer Society, pp. $47-53,2011$

[41] Johnson, C.M., McIlwain, S., Gray, O., Willson, B., and Vorderstrasse, A., "Creating a Sustainable Collaborative Consumer Health Application for Chronic Disease SelfManagement", Journal of Biomedical Informatics, Volume 71, pp.198-206, 2017. 